\title{
INTERNAL FORCES TESTS IN RETAINING WALIS OF ROAD EMBANKMENTS
}

The subjects of this paper are resistance structures constituted by reinforced soil applied in highway engineering. Test results carried out on laboratory models are presented, leading to the estimation of the size and shape of the wedge of the reinforced soil embankment block, in the boundary state of active pressure. The task was conducted in the following two stages: on the basis of measured horizontal strains of the embankment (unitary lateral pressures) and reinforcing dowels - with the application of sensors of electro-resistant tensometry. The slip curve, determining the searched block wedge, is formed by the points of maximal normal stress occurring in the reinforcement dowels located in the horizontal layers. The slip curve divides the embankment area into two zones: active (block wedge) and passive, in which dowel anchorage takes place.

\section{Introduction}

The classical reinforcement soil, being the subject of analysis, has found the broadest application in the field of resistance structures (retaining walls of road embankments, bridge heads, etc.). The necessary length of reinforcement dowels is calculated as a sum of lengths in the active and passive zone when designing the retaining structures made of reinforced soil. The curve of maximal tensile forces divides the soil embankment into two zones mentioned before. Therefore, the mode of accepting the shape of the curve influences the structure designing economy. The article presents a testing method, enabling determination of the value of block wedge reduction in the vertical wall embankment of non-cohesive soil reinforced with horizontal dowels, in reference to an identical structure with no reinforcement. The size and shape of the wedge of soil embankment block with reinforcement was estimated in the boundary state of active pressure. The task was performed as a test (in two stages), on the basis of measured strains of reinforcement dowels, with the application of sensors of electro-resistant tensometry.

\section{Measurement rule of block wedge}

The subject of the tests are measurements of: horizontal strains of loaded soil embankment (medium-grained dry river sand), carried out in the plane of the retaining wall of model [6] as well as strain measurements of reinforcement dowels by means of electro-resistant tensometry.

In the first stage, the block wedge in the boundary state of the active pressure of the soil embankment was determined on the basis of the estimation of the value of the zone of influence of the external load of the soil surcharge (measured perpendicularly to the plane of the retaining wall of the embankment) on the value of the embankment horizontal pressure, read out at the wall plane. The test method consists of the analysis of processes of changes of the value of soil pressure on the retaining wall, as the distance of the test load of the surcharge (sectional, executed by means of the so-called stemple) from the measurement retaining wall increases. The range of the block wedge in the pressure boundary state was determined as parameter ly,boundary in particular measurement levels, on the basis of the analysis of the course of pressure dwindling phenomenon, as the loading stemple moves further apart from the wall. Then (stage II), parameter ly,boundary was compared with the location of maximal normal stresses in dowels located in horizontal layers. The details of the test method, the stand and the model design are provided in the elaboration works [6, 7, 8, 9] (Fig. 1).

The adopted test method enables to preserve relative specificity of the testing conditions and the planned change of one of the parameters with other parameters unchanged.

\section{Profile and location of reinforcement dowels}

One of the test goals was to determine forces in reinforcement in the form of strain measurements. The application of limp dowels could guarantee the initiation of strains, possible to be measured with the use of soil surcharge load in the tests (the load was called "special" or "testing").

Dowels in the form of limp steel belts, with the symbol of 50HSA, length of $l_{a}<1.80 \mathrm{~m}$ (length of cubicoidal container with model - soil embankment amounts to $L=2.00 \mathrm{~m}$ ) and intersection of $b_{a} \times g_{a}=0.024 \mathrm{~m} \times 0.001 \mathrm{~m} \mathrm{(b-dowel} \mathrm{width,} \mathrm{g}$ - dowel thickness) were used as reinforcement. The soil centre was reinforced with belts of smooth surface and with notches (in the form

\footnotetext{
* ${ }^{1}$ Andrzej Surowiecki, ${ }^{2}$ Edward Hutnik

${ }^{1}$ Technical University of Wrocław, Institute of Civil Engineering; Agricultural Academy of Wrocław, Institute of Civil Engineering and Landscape Architecture

${ }^{2}$ Agricultural Academy of Wrocław, Institute of Civil Engineering and Landscape Architecture
} 
of angles), fastened with electric welding on both sides. The notches, shaping the belts surface spatially, cause the increase of dowels resistance to pulling out from the soil centre.
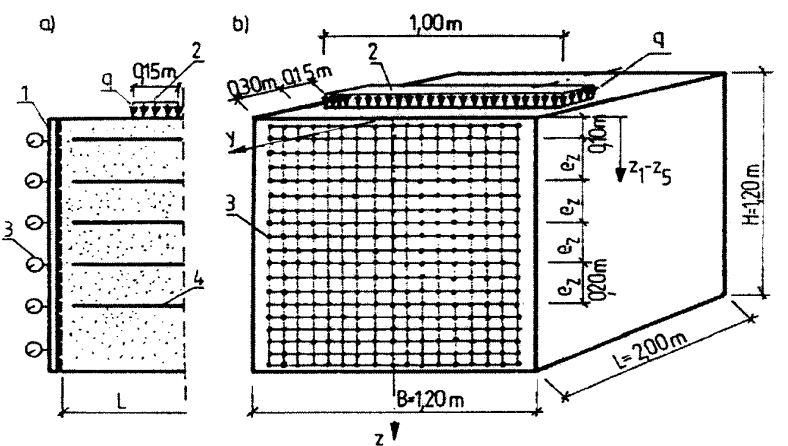

Fig. 1. Design and basic parameters of test stand: $a$ - block of longitudinal vertical intersection; $b$ - general view; 1 - measurement wall (frontal one); 2 - load-carrying plate; 3 - horizontal rooms sensors; 4 - reinforcement belts

In the model designed for laboratory tests, the reinforcement was distributed in horizontal layers with identical vertical spacing $e_{z}=0.195 \mathrm{~m}$. In each layer, the dowels were located paralelly to the longitudinal axis of the container, with the preservation of identical axial horizontal spacing, accepted in turn: $e_{x}=0.11 ; 0.17$ and $0.23 \mathrm{~m}$. The determined three sizes of dowel length $l_{a}$ in the model form a sequence of terms: $1.0 l_{a}(\mathrm{~A}, \mathrm{~B}, \mathrm{C}, \mathrm{D}$ system); 0.72 $l_{a}(\mathrm{E}) ; 0.55 l_{a}(\mathrm{~F})$. The maximal dowel length $l_{a}=1.80 \mathrm{~m}(\mathrm{~A}, \mathrm{~B}$, $\mathrm{C}, \mathrm{D}$ systems) includes not only the area of the block wedge in the soil embankment (dry coarse-grained river sand was used) but also the anchoring section.

\section{Estimation of body of block on basis of horizontal pressure measurements at plane of retaining wall (stage I)}

The charts illustrating the change of the determined (approximated) value of the block wedge in the reinforced and non-reinforced soil embankment are presented in figures 2 and 3. The surface areas included between respective curves (Fig. 3) express the reduction of the block body as a result of placing notches on the dowel surface. The test curves were approximated with mathematical functions, for example curves from figure $2\left(C_{c}\right.$ is a correlation co-efficient):

I for non-reinforced sand:

$v=a e^{b u}, a=3.78810^{-2}, b=3.587, C_{c}=0.918$;

II for non-reinforced sand:

$v=a e^{b u}, a=6.15910^{-3}, b=4.464, C_{c}=0.906$;

I for reinforced sand:

$v=a e^{b u}, a=1.05310^{-2}, b=6.119, C_{c}=0.920$;

II for reinforced sand:

$v=a e^{b u}, a=1.08510^{-3}, b=11.221, C_{c}=0.908 ;$

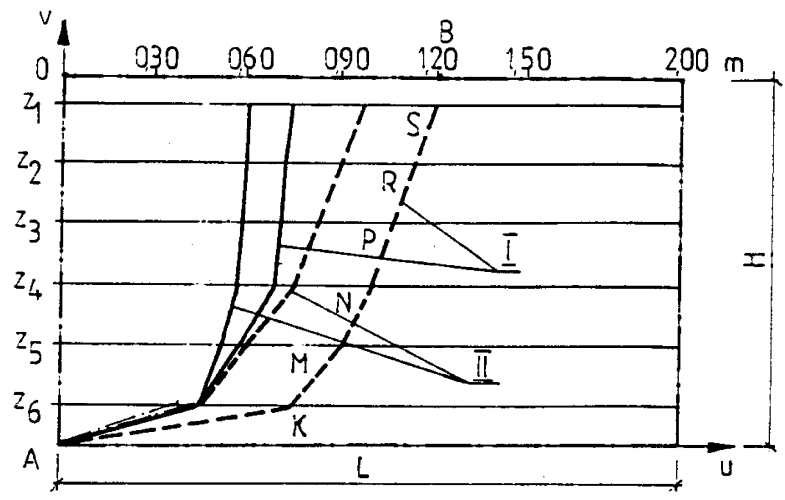

Fig. 2. Range of block wedge estimated in test $l_{y \text { gr }}$ and course of slip curve: - - - non-reinforced embankment; - - - reinforced with belts with no notches (A system); I - loosely poured; II - pre-consolidated; z1-z6 - measurement levels

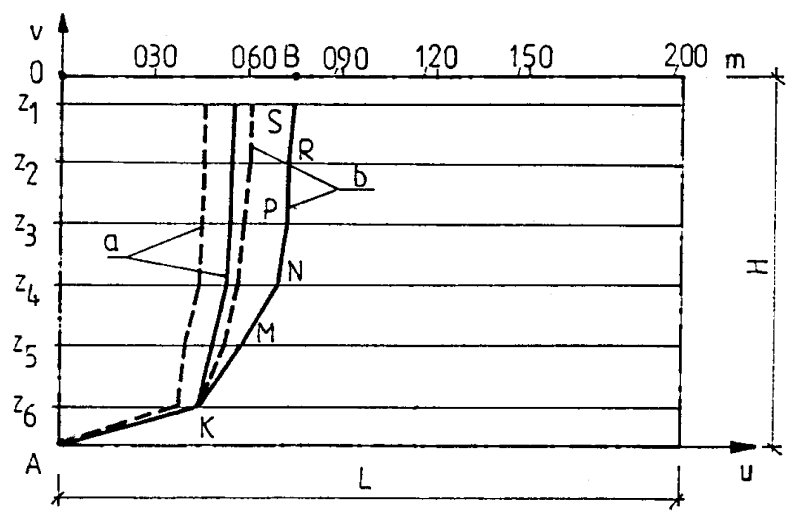

Fig. 3. Value of block wedge and course of slip curve from tests, depending on type of reinforcement (A system): - - - loosely poured embankment; - - - pre-consolidated; $a$ - belts with notches; $b$ - without notches

\section{Estimation of block body on basis of distribution of maximal normal stresses in reinforcement (stage II)}

\section{Description of reinforcement strain measurements}

The special load of the surcharge introduced in the tests results only from the test method and is mainly a factor forcing the formation of the block wedge. The static band load was executed through vertical thrust of a stiff steel stemple, located perpendicularly in relation to the horizontal projection of the container. The details of the course of tests regarding the conditions of the height of the test load are available in the monograph [5]. Also, it is worth noticing that identical load does not cause, to the same extent, the anticipated phenomena of the formation and movement of the block wedge in the soil centre differing with regard to the degree of consolidation and amount of reinforcement. Therefore, the load accepted for test purposes should be treated as approximated, but in admissible limits.

The measurements of unitary reinforcement strains $\epsilon$ carried out with the method of electro-resistant tensometry were used in 
tests with reinforcement systems: A ( 9 dowels in layer), B ( 6 dowels in layer) and C ( 4 belts in layer) - in all cases the dowels included notches on the surface. Yet, the extensometers were stuck only on two belts in each layer so as to reduce the number of connection cables maximally. These ducts, running, out of necessity, near reinforcement through the soil centre are the reason for disturbances during the recording of dowel strains, and artificially (which is undesirable) support the dowels resistance to being taken out from the centre. 10 extensometers were stuck on each belt, 5 pieces on each side. The location of extensometers along the belt length was anticipated in a way enabling to include mainly the active zone (i.e. block wedge range) and partially the anchoring zone. The extensometers were coated with resin, protecting them against mechanical damage and dampness. The measurements and recording of extensometers read-outs were carried out with a multi-point automatic kit designed for strain tests, consisting of an automatic extensometric bridge, an apparatus controlling the measurement and extensometers connecting, extensometric boxes and a microcomputer with a printer. The strains measurement in the reinforcement belts was conducted in turn for two states of surcharge loading: $q=37.02 \mathrm{kPa}$ i $61.69 \mathrm{kPa}=q_{\max }$. The values of normal stresses in the reinforcement obtained from the micro-computer are expressed with a classic Hook's dependence: $\sigma=E \epsilon$.

\section{Normal stresses in reinforcement}

Figure 4 shows the stress diagrams along the dowel located at the level of $z_{2}=0.29 \mathrm{~m}$, depending on the surcharge load with a stemple in the distance of $l_{y}=0.30 \mathrm{~m}$ from the measurement wall. These diagrams can represent the strained axis of the reinforcement with the length of $l_{a}$.

Figure 5 illustrates the stress distribution along belts located at the levels of $z_{2}=0.29 \mathrm{~m}$ and $z_{3}=0.485 \mathrm{~m}$, depending on the level of sand backfill density. The stresses in the reinforcement in the sand embankment are lower than in a loosely poured embankment.

a)

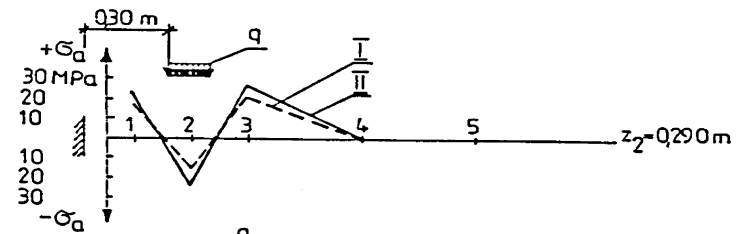

b)

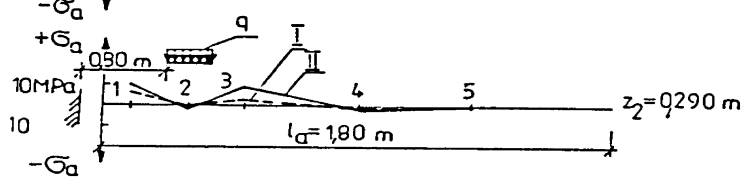

Fig. 4. Diagrams of normal stress distribution in upper surface of reinforcement dowel, depending on load: a - loosely poured sand; $b$ - pre-consolidated; $I$ - load $q=37.02 \mathrm{kPa} ; \mathrm{II}-q=61.69 \mathrm{kPa}$;

1-5 - extensometers numeration on upper surface of dowel (A reinforcement system)

Figure 6 presents the stress distribution in the reinforcement dowels on five measurement levels for the embankment consisting of loosely poured sand, reinforced in A system. The surcharge load $q=61.69 \mathrm{kPa}$ is located in the distance of $l_{y}=0.30$ (curve a) or $l_{y}=0.60 \mathrm{~m}$ (curve b) from the retaining wall. The stemple location from the wall amounting to $l_{y}=0.60 \mathrm{~m}$ is a minimal distance, at which the soil pressure on the retaining wall (i.e. in this location of the stemple, block wedge in the embankment is fully formed) was not observed.

a)

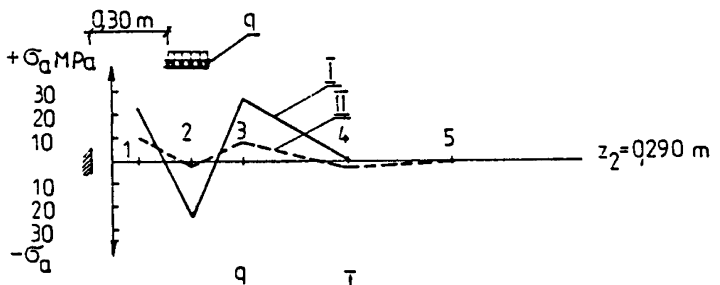

b)

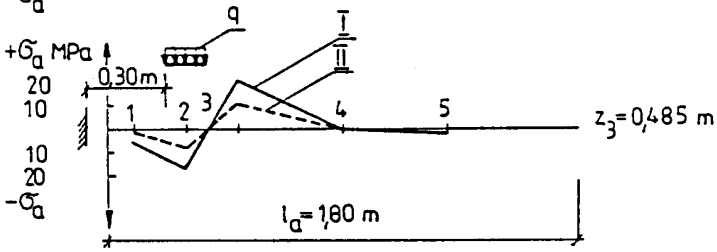

Fig. 5. Diagrams of normal stress distribution in upper surface of reinforcement dowel at level of $z_{2}(a) i z_{3}(b)$. Load $q=61.69 \mathrm{kPa}$ in distance of $l_{v}=0.30 \mathrm{~m} ; I$ - loosely poured sand; II - pre-consolidated sand
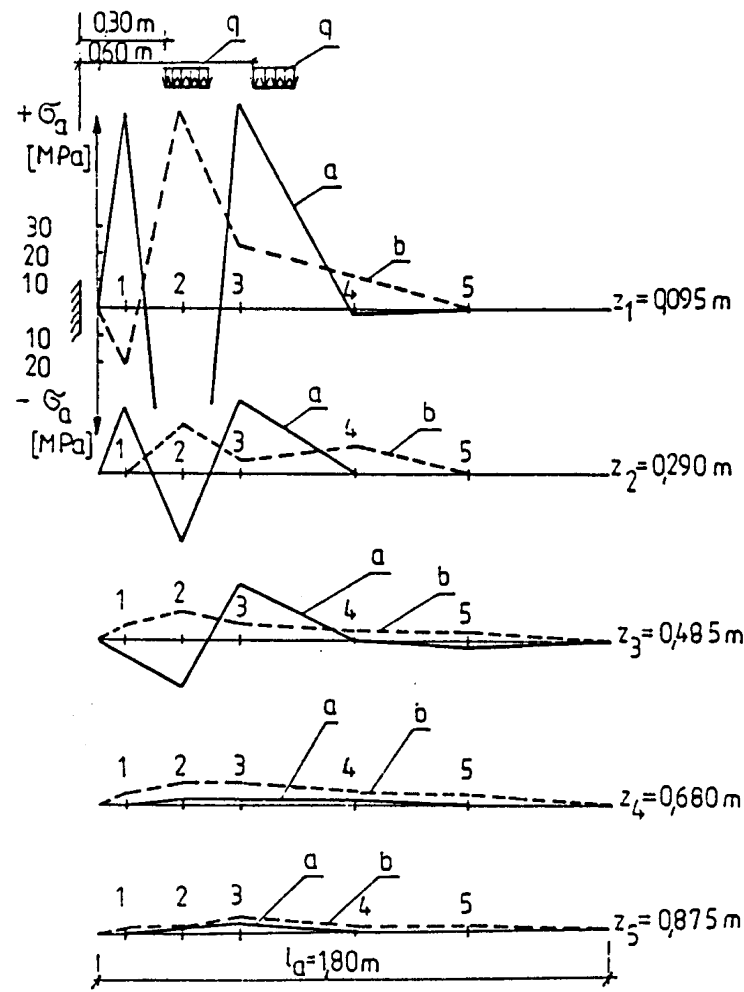

Fig. 6. Diagrams of normal stress distribution on upper surface of reinforcement dowels in loosely poured embankment: $a$ - stemple in distance of $l_{y}=0.30 \mathrm{~m} ; b-l y=0.60 \mathrm{~m}=l_{y \text {,boundary }}$,

$z_{1}-z_{5}$ - reinforcement location levels; 1 - 5 - extensometer numeration; reinforcement system $A$ 
Fig. 7 also shows the diagrams of stress distribution in the reinforcement dowels on five measurement levels, depending on the load-carrying stemple relocations, as in fig. 6 , but for the preconsolidated embankment.
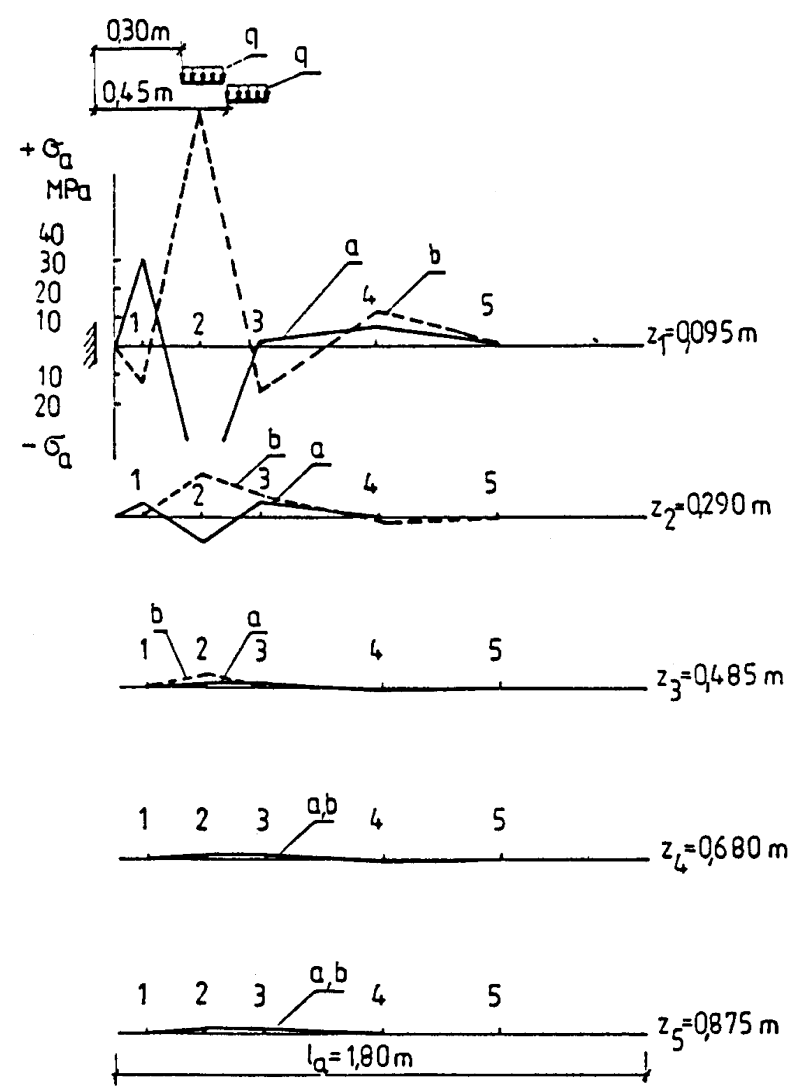

Fig. 7. Diagrams of normal stress distribution in upper surface of reinforcement dowels in pre-consolidated embankment: $a$ - stemple in distance of $l_{y}=0.30 \mathrm{~m} ; b-l_{y}=0.45 \mathrm{~m}=l_{y, \text { boundary }}, z_{1}-z_{5}$-location

levels of reinforcement layers; 1 - 5 - extensometer numeration; reinforcement system $A$

\section{Estimation of slip surface location}

As results from tests concerning normal stresses in the reinforcement, the profile of the strain of reinforcement belts changes as the distance of the load-carrying stemple from the measurement wall increases. If the distance of the stemple from the wall reaches the boundary value $l_{y} \cong l_{y, \text { boundary }}$ (stemple locations $l_{y} \geq l_{y, \text { boundary }}$ are not accompanied by any increases of soil pressure on the wall), only the tensile stresses will occur on the upper surface of the belts. This phenomenon may confirm the fact of the block wedge formation on the complete embankment height. The belts at the highest level are an exception, where the extensometer No 1 shows compressive stress $\left(-\sigma_{a}\right)$ in their upper surface. This phenomenon repeated in all tests (for a different number of dowels in the model) and is a result of direct, disturbing band influence of the load, which the belts at this level are subject to. The diagrams show that in belts located at lower levels (e.g. $z_{4}$ and $z_{5}$ ), the stresses of one character (tensile) occur as early as at shorter distances of the stemple from the retaining wall. Therefore, one may suppose that the embankment damage is of a progressive character, thus the block wedge is formed gradually, gaining first a final shape in the lower zone.

It is known from literature regarding reinforced soil tests [Long, Schlosser 1974, 78] that a potential slip curve in the state of stress boundary equilibrium can be obtained graphically: it is a geometric place of maximal tensile forces in particular reinforcement layers. Proceeding analogically in relation to the points of maximal ordinates occurrence, concerning curve (b) from figures 6 and 7, the course of the slip curve was determined in a test in the reinforced sand embankment (Fig. 8). The accuracy of estimation is connected, among others, with the number of extensometer location points and their distribution on the reinforcement belts.

As results from relevant literature [1], slip along surface can be accepted only for the non-coherence soil. Since the reinforced soil has features of anisotropic coherence $[2,3,4,5]$, the slip curve should be adopted and identified with the line of soil damage with cohesion.

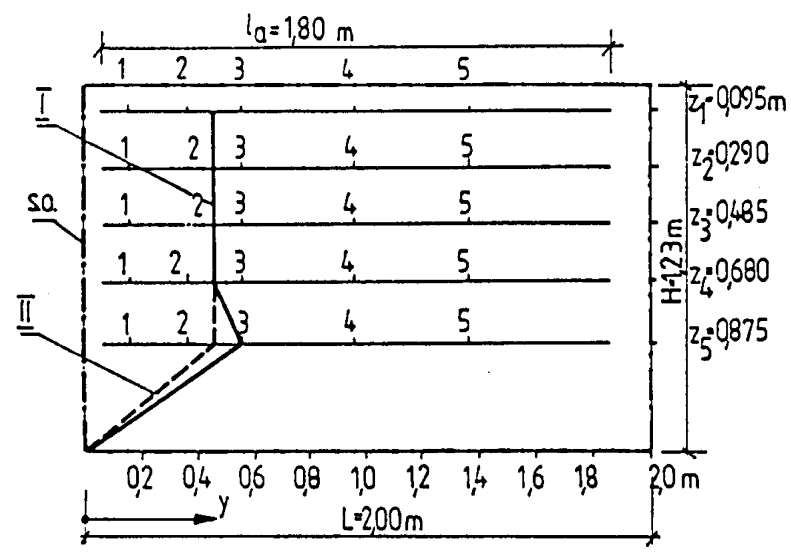

Fig. 8. Curve connecting points of maximal tensile stresses in reinforcement (approximated estimation): 1 - 5 - extensometers numbers stuck to upper surface of dowels; $z_{1}-z_{5}-$ numbers of measurement levels of retaining wall; I - embankment of loosely poured sand; II - pre-consolidated embankment

\section{Summary}

The sizes and shape of the wedge of reinforced soil embankment block were estimated, in the boundary state of active pressure. The task was performed as a test (in two stages), on the basis of measured strains of reinforcement dowels, by means of electro-resistant tensometric sensors. The points of maximal normal stresses occurring in reinforcement dowels located in horizontal layers form a slip curve, separating the searched block wedge from the retaining wall plane. The basis for analysis were the measurements of: horizontal strains of loaded soil embankment, carried out at the plane of a model with considerable dimensions, and the measure- 
ments of reinforcement dowel strains by means of electro-resistant tensometry method.

In stage I, the wedge of the block in the boundary state of active pressure of the soil embankment was determined on the basis of the estimation of the value of the zone of influence of the external load of soil surcharge (measured perpendicularly to the plane of the retaining wall of the embankment) on the value of the horizontal pressure of the embankment, read out at the wall plane. The testing method consists of the analysis of the process of changes of the value of soil pressure on the retaining wall, as the distance of the test loading of surcharge (sectional, realised by means of the so-called stemple) from the measurement retaining wall increases.
On the basis of the analysis of the course of the phenomenon of pressure dwindling, as the load-carrying stemple moves further apart from the wall, the range of the block of the wedge was determined, in the boundary state of active pressure as parameter $l_{y, \text { boundary }}$ in particular measurement levels. Then (stage II), parameter $l_{y, \text { boundary }}$ was compared with the location of maximal normal stresses in dowels, at the level of the embankment.

Summing up, the usability of tensometric tests for examining the operation of loaded engineering structures was proved. The measurement of normal stresses in the reinforcement enabled quite a precise specification of the shape of the slip surface in the reinforced soil embankment.

\section{References}

[1] GLAZER, Z.: Mechanika gruntów [Soil mechanics], Wyd. Geologiczne [Geological Publishing House], Warszawa 1987.

[2] LONG, N. T.: Badania gruntów zbrojonych - Wybrane zagadnienia geotechniki [Reinforced soil tests - Selected problems of geotechnics], PAN-IBW, Wrocław, Ossolineum, 1978, p. 185 - 210.

[3] LONG, N. T., SCHLOSSER, F.: Wymiarowanie murów z gruntów zbrojonych - Wybrane zagadnienia geotechniki [Dimensioning of reinforced soil masonry - Selected problems of geotechnics] - , PAN-IBW, Wrocław, Ossolineum, 1978, p. 211 - 237.

[4] LONG, N. T., SCHLOSSER, F.: Zasada dziatania i zachowanie się gruntu zbrojonego - Wybrane zagadnienia geotechniki [Principle of operation and profile of reinforced soil - Selected problems of geotechnics], PAN-IBW, Wrocław, Ossolineum, 1978, p. 157 - 184.

[5] SCHLOSSER, F.: Grunt zbrojony w budownictwie ladowym [Reinforced soil in civil engineering], Archiwum Hydrotechniki [Hydraulic engineering archive], vol. XXI, 1974, sheet 2, p. 299 - 336.

[6] SUROWIECKI, A.: Analiza doświadczalna poziomego parcia gruntu zbrojonego oporowych konstrukcji podtorza [Test analysis of horizontal pressure of reinforced soil of retaining structures of track substructure], Pr. Nauk. Instytutu Inż. Lądowej [Work of Scientific Institute of Civil Engineering] P. Wr., No 41, Seria: Monografie [Series: Monographs] No 15, Wrocław 1993.

[7] SUROWIECKI, A.: Laboruntersuchungen von mechanischen Eigenschaften bewehrter lockerer Bodenschichten, Bautechnik, Jg. 71, H. 11, 1994, p. $707-711$.

[8] SUROWIECKI, A.: Badania doświadczalne klina blocku ściany oporowej z gruntu zbrojonego [Tests of the wedge of a block of a retaining wall of reinforced soil]. Inżynieria Morska i Geotechnika [Naval Engineering and Geotechnics], No 2, Gdańsk, 1995 , p. 68 - 72.

[9] SUROWIECKI, A.: Interaction between reinforced soil components, Studia Geotechnica et Mechanica, Vol. XX, No. 1/2, Wrocław 1998, p. $43-61$. 